\title{
Creating a Functional Interdependency Map for Supporting the "Act of Improvement" in Business Process Improvement Projects
}

\author{
Florian Johannsen, University of Applied Sciences Schmalkalden, Germany* \\ Gregor Zellner, University of Applied Sciences Regensburg, Germany \\ Philipp Griesberger, University of Regensburg, Germany
}

\begin{abstract}
Business process improvement (BPI) is of high priority for practitioners. But especially the most value-adding phase in a BPI project, namely the "act of improvement," is insufficiently supported despite the many existing methods and techniques. Until now, it has been largely unclear as to what degree existing BPI techniques support each other and are interrelated with one another. Thus, the purpose of this paper is to investigate the functional interdependencies between BPI techniques to get a better understanding for the beneficial synergies between the BPI techniques and to provide a basis for purposefully combining them within projects. Based on the functional interdependencies, a graphical "functional interdependency map" is developed and its usability demonstrated in an experiment. The paper is valuable for academics and practitioners alike because the impact of BPI on organizational performance is high.
\end{abstract}

\section{KEYWORDS}

BPI Technique, Business Process, Case Study, Conceptual Model, Design Science, Experiment, Map, Metamodel

\section{INTRODUCTION}

New technologies have tremendously reshaped the service sector in recent years (Beatson et al., 2007; Noh et al., 2016). Thereby, in times of "Industry 4.0", even more and more manufacturing companies complement their product portfolio by "smart services" (e.g., predictive maintenance) to achieve competitive advantage (Acatech, 2016; Herterich et al., 2015; Pöppelbuß, 2018). Against this background, Business Process Improvement (BPI) (cf. Harrington, 1991) ranks high on the agenda of CIOs (cf. Acatech, 2016; Charles, 2017; Harmon \& Garcia, 2020) as companies are engaged in the integration of digital technologies with their business processes to assure sustainable customer satisfaction (Gimpel et al., 2018; Gimpel \& Röglinger, 2015).

According to a study by Harmon \& Garcia (2020), which included 129 process experts, the need to improve customer satisfaction to remain competitive is judged to be one of the major drivers for BPI projects. Accordingly, major process redesign projects are in the center of attention in the years to come (cf. Harmon \& Garcia, 2020) to foster the integration of new technologies (e.g., 3D-printing, Augmented Reality, Internet of Things etc.) (e.g., Belkeziz \& Jarir, 2020; Kinnunen et al., 2018) 
with current practices to increase process quality (cf. Hänisch, 2017) and ensure an organization's success (cf. Galli, 2020). For that purpose, a variety of frameworks, methodologies, techniques, and tools were developed for conducting BPI projects (e.g., PROMET - Process Method, IBM Business Transformation Methodology, (Lean) Six Sigma, etc.) (cf. Dalmaris et al., 2007; Österle, 1995; Pande et al., 2014; Shin \& Jemella, 2002; Sudha \& Kavita, 2019; Zellner, 2011).

In this respect, the most value-adding phase in a BPI project is the "act of improvement" (e.g., Forster, 2006; Griesberger et al., 2011; Reijers \& Limam Mansar, 2005; Sharp \& McDermott, 2008; Valiris \& Glykas, 1999; Vergidis et al., 2006). The term "act of improvement" describes an active operation, which is executed on an element of a business process (e.g., activity, control flow or resource) and helps to transform the business process from an "as-is" to a "to-be state" (Griesberger et al., 2011; Zellner, 2011).

In existing BPI approaches (e.g., Antony, 2006; Zellner, 2011), this "act of improvement" is usually embedded in singular "activities" or "phases" of the procedure model, e.g., the phase "Improve" of the Six Sigma cycle (Pande et al., 2014; Snee \& Hoerl, 2003) or the activity "redesign process" in the seven-step-methodology of Adesola \& Baines (2005). Despite the availability of holistic procedure models (e.g., Six Sigma cycle) that incorporate activities/phases for process improvement and supportive BPI techniques (e.g., Best-Value Future-State Solution) (cf. Andersen, 1999; Griesberger et al., 2011; Harrington \& Lomax, 2000; Meran et al., 2013) the "act of improvement" itself is often perceived as a "black box" in practice (Ramaswamy et al., 2018). Hence, there is no theoretical guidance on how to perform or structure the task (Forster, 2006; Reijers \& Limam Mansar, 2005; Valiris \& Glykas, 1999; Zellner, 2013). As a result, the transformation of a process from the "as-is" to the "to-be state" - by the modification of particular business process elements - is insufficiently specified (Falk et al., 2013; Lang et al., 2015) and often done in an "ad-hoc" fashion shaped by employees' subjective perceptions (e.g., Nwabueze, 2012).

Generally, BPI techniques are applied to guide the generation of suggestions for process improvement (cf. Gutzwiller, 1994) in BPI projects and support the "act of improvement" that way. Though, practitioners are frequently overstrained in choosing suitable BPI techniques for projects (Hagemeyer et al., 2006; Johannsen et al., 2015). Moreover, little understanding exists on how BPI techniques can be purposefully combined to structure the "act of improvement" (cf. Johannsen, 2017). At this point, "functional interdependencies" are discussed in literature as a means to explain beneficial synergies between BPI techniques (Bruhn, 2019; Johannsen, 2017). Functional interdependencies analyze the conjoint application of BPI techniques by considering their underlying functioning, i.e., the way each technique converts input to output information.

The authors of this study argue that the explication of beneficial functional interdependencies between BPI techniques helps practitioners (managers and employees) to better structure the "act of improvement", because it gets evident, which techniques purposefully complement each other and support the further specification of results. To explicate functional interdependencies, we propose to use conceptual models, as these have proven beneficial in practice to reduce complexity and outline relations between concepts for various domains (Anaby-Tavor et al., 2010). We therefore ask the following research question:

How can functional interdependencies be visualized (by help of a conceptual model) to facilitate the selection of BPI techniques to support the "act of improvement"?

The major aim of this study is to create a conceptual model in form of a "map" (cf. Anaby-Tavor et al., 2010) to unveil functional interdependencies between BPI techniques that support the "act of improvement". That way, the user is supported during the selection and combination of BPI techniques for a BPI initiative, which gives structure to the "act of improvement".

The remainder of this paper is organized as follows: First, theoretical foundations and the research procedure are presented. Afterwards, the design of the map to specify functional interdependencies is 
explained. Then, the results of an experiment are shown, which was performed to assess the usability of the map. Finally, the benefits of this research are discussed, limitations described and an outlook is given.

\section{BACKGROUND}

\section{Business Process Improvement}

Business process improvement (BPI) is an approach to increase the effectiveness and efficiency of business processes, which provide output to internal and external customers (Harrington, 1991; Page, 2015). BPI can be achieved by changing the state of the mandatory elements of a business process (e.g., activity, control flow, resource, etc.) (Griesberger et al., 2011). "Thereby the state after the change exceeds the state before the change in such a way that the degree of accomplishing organizational goals is increased, which improves the performance of the business process" (Griesberger et al., 2011, p. 3).

Many different terms were introduced in literature to address the improvement of business processes (Zairi \& Sinclair, 1995), since the appearance of "business process re-engineering (BPR)" as a central discipline for business improvement (cf. Baines, 1996; Johnston, 2012). Some examples are "business process improvement (BPI)" (Harrington, 1991; Page, 2015), "business process redesign" (Davenport \& Short, 1990; Kettler et al., 2019), "business (process) re-engineering (BPR)" (Hammer, 1990; Johnston, 2012; Sudha \& Kavita, 2019), "core process redesign" (Al-Hudhaif, 2009; Kaplan \& Murdock, 1991), or "continuous improvement process" (Deming, 2000; Gisi, 2018; Imai, 1986; Yankelevitch \& Kuhl, 2015) just to mention a few.

Although many BPI methods (e.g., Six Sigma, Total Quality Management, Lean Management, etc.) (cf. Aikhuele \& Turan, 2018; Galli, 2018a, 2018b; Pande et al., 2014; Womack et al., 2000) were developed at manufacturing companies, they are increasingly applied in the service sector as well (e.g., Bouranta et al., 2019; Breyfogle et al., 2001). To consider the inherent characteristics of services (e.g., heterogeneity, inseparability, perishability, etc.) (Wirtz \& Lovelock, 2016), several established methods were modified and variants such as "Six Sigma for service processes" (cf. Antony, 2006) or "Lean for Service" (cf. Bicheno, 2008; Vignesh et al., 2016) came up (Bouranta et al., 2019).

\section{BPI Techniques and Functional Interdependencies}

In literature, the terms "method", "technique" and "tool" are often used synonymously or inconsistently (cf. Grünberg, 2003; Johannsen \& Leist, 2009; McQuater et al., 1995; Uluskan, 2016). According to Kettinger et al. (1997, p. 58), a technique is “(...) a set of precisely described procedures for achieving a standard task". Equally, a technique is described as a detailed guideline to create results (Pacicco et al., 2010). A technique receives some sort of input information that is transformed to output information (result) by following a certain procedure (Hagemeyer et al., 2006). Techniques are usually part of a method (e.g., the "7x7 Toolbox" is part of the Six Sigma method) (Kettinger et al., 1997; Magnusson et al., 2004; Okes, 2002; Zellner, 2011).

An investigation concerning BPI techniques was performed by Griesberger et al. (2011). This research included 36 techniques which are shown in Table 1 . In the research by Griesberger et al. (2011) a technique was considered as relevant for the study in case it could either be used for the generation of new solutions or for problem solving; i.e. these techniques are applied during the "improvement stage" of a BPI project and foster the generation of a solution that either leads to the desired improvement or to the correction of a problem.

Generally, Bruhn (2019) identifies functional, temporal as well as hierarchical interdependencies between BPI techniques. Temporal interdependencies address the sequencing of BPI techniques from a chronological perspective, while the hierarchical interdependencies distinguish whether a BPI technique serves strategic or operational goals (Bruhn, 2019). The interplay between BPI techniques and thus beneficial synergies are determined by the functional interdependencies (Bruhn, 2019) (see 
Table 1. BPI techniques for the act of improvement (Griesberger et al., 2011)

\begin{tabular}{|c|c|c|c|c|}
\hline No. & Technique (Reference) & No. & \multicolumn{2}{|l|}{ Technique (Reference) } \\
\hline 1 & Anti-Solution Brainstorming ${ }^{(3)}$ & 19 & Other Points of View (OPV) ${ }^{(2)}$ & \\
\hline 2 & Best-Value Future-State Solution (BVFS) ${ }^{(2)}$ & 20 & Potential problem analysis (PPA) ${ }^{(4 ; 6)}$ & \\
\hline 3 & Brainstorming $(1 ; 2 ; 3 ; 4 ; 5 ; 6 ; 7)$ & 21 & Problem prevention plan ${ }^{(4 ; 6)}$ & \\
\hline 4 & Brainwriting ${ }^{(1 ; 3 ; 4)}$ & 22 & Process Cycle Time Reduction ${ }^{(1 ; 2)}$ & \\
\hline 5 & Bureaucracy Elimination ${ }^{(1 ; 2)}$ & 23 & Process decision program chart ${ }^{(1 ; 2 ; 4)}$ & \\
\hline 6 & Cause and effect analysis $(1 ; 2 ; 3 ; 4 ; 5 ; 6 ; 7)$ & 24 & Process Simplification ${ }^{(2)}$ & \\
\hline 7 & Error proofing (pokayoke) ${ }^{(2 ; 3 ; 4 ; 6)}$ & 25 & Quality function deployment (QFD) ${ }^{(1 ; 2 ; 4 ; 5 ; 6)}$ & \\
\hline 8 & Evolutionary operation (EVOP) ${ }^{(4)}$ & 26 & Redundancy Elimination ${ }^{(1)}$ & \\
\hline 9 & Failure mode and effect analysis (FMEA) ${ }^{(2 ; 3 ; 4 ; 6 ; 7)}$ & 27 & Replenishment Pull System ${ }^{(3)}$ & \\
\hline 10 & Fast Action Solution Technique (FAST) ${ }^{(2)}$ & 28 & Robust design (off-line quality control) ${ }^{(4)}$ & \\
\hline 11 & Generic Pull System ${ }^{(3)}$ & 29 & Setup Time Reduction ${ }^{(3)}$ & \\
\hline 12 & Idealizing ${ }^{(1)}$ & 30 & Should-be Process Map ${ }^{(6)}$ & \\
\hline 13 & Mind mapping ${ }^{(2 ; 4)}$ & 31 & Snowballing ${ }^{(4)}$ & \\
\hline 14 & Morphological forced connections ${ }^{(4)}$ & 32 & Taguchi methods ${ }^{(4)}$ & \\
\hline 15 & Negative Analysis ${ }^{(2)}$ & 33 & The Importance of Speed ${ }^{(3)}$ & \\
\hline 16 & Nominal group technique $(1 ; 2 ; 3 ; 4 ; 5)$ & 34 & Theory of Constraint (TOC) ${ }^{(3)}$ & \\
\hline 17 & Objective ranking ${ }^{(4)}$ & 35 & Total productive maintenance ${ }^{(3 ; 4)}$ & \\
\hline 18 & Opportunity cycle (2) & 36 & Visioning / Imagineering $(2 ; 4 ; 5 ; 6)$ & \\
\hline
\end{tabular}

Table 2). Functional interdependencies focus on techniques' way of processing input information to receive output information. In this regards, complementary, conditional, substituting, indifferent and rivalling interdependencies can be differentiated (Bruhn, 2019) (Table 2).

Table 2. Functional interdependencies according to Bruhn (2019)

\section{Types of functional interdependencies}

Conditional: A BPI technique requires another technique to be applied in addition.

Complementary: Two or more BPI techniques support each other during application.

Substituting: The application of two or more BPI techniques leads to identical types of output information (e.g., process map).

Indifferent: BPI techniques do not influence each other during application.

Rivalling: The application of certain BPI techniques produces contradictory results.

Thereby, the beneficial synergies between BPI techniques are principally specified by conditional and complementary interdependencies. Complementary interdependencies are given, if the output information of a technique "A" provides useful information, which facilitates the use of a technique 
"B" (Bruhn, 2019). In case of conditional interdependencies, the output information produced by technique "A" is mandatory for using technique "B" (Bruhn, 2019). For example, one cannot use the QFD (Quality Function Deployment) technique (Akao, 1990; Knorr \& Friedrich, 2016; Rahpeyma \& Zarei, 2018) without knowing the customer requirements, which have to be provided by other techniques (e.g., "CTQ-Matrix" (Meran et al., 2013)). However, in practice the differentiation between complementary and conditional interdependencies is hard to keep up. Considering the QFD technique for instance, one may argue that employees usually are aware of customer requirements and hence are able to use the QFD technique directly without any other techniques having to be applied additionally. Therefore, we consider complementary and conditional interdependencies in conjunction in the following, as both refer to a beneficial interplay of BPI techniques by the exchange of information. In a study by Johannsen (2017), indicators for functional interdependencies were identified for a set of quality techniques on a metamodel level. Whereas this approach is helpful for software developers in the BPI field (cf. Johannsen, 2017), employees require a more pragmatic and easy-to-understand guidance for being able to plan the "act of improvement" properly. At this point, graphical representations, e.g., in form of a "map", have established in practice to capture knowledge (Anaby-Tavor et al., 2010; Hall, 2006); in our field this concerns knowledge about the functional interdependencies between BPI techniques.

\section{PROCEDURE OF THE INVESTIGATION}

This paper follows the Design Research procedure as proposed by Peffers et al. (2007), which was adapted for the research at hand. Figure 1 outlines the procedure.

Figure 1. Procedure of the research (adapted for this study from: (Peffers et al., 2007))

\begin{tabular}{|c|c|c|c|c|}
\hline $\begin{array}{l}\square: \text { Focus of this paper } \\
\square \text { : Future work }\end{array}$ & & proc & is iteration & \\
\hline Problem & $\begin{array}{l}\text { Objectives of a } \\
\text { Solution }\end{array}$ & $\begin{array}{l}\text { Design \& } \\
\text { Development }\end{array}$ & Demonstration & $\begin{array}{l}\text { Evaluation \& } \\
\text { Communication }\end{array}$ \\
\hline $\begin{array}{l}\text { The "act of improvement" in } \\
\text { BPI is often done in an "ad-hoc" } \\
\text { manner and there is a lack of } \\
\text { understanding on beneficial } \\
\text { synergies between BPI } \\
\text { techniques. }\end{array}$ & $\begin{array}{l}\text { Requirements on } \\
\text { the map for } \\
\text { visualizing } \\
\text { beneficial } \\
\text { functional } \\
\text { interdependencies. }\end{array}$ & Design of the map. & $\begin{array}{l}\text { Application of } \\
\text { the map in a } \\
\text { laboratory } \\
\text { experiment. }\end{array}$ & $\begin{array}{l}\text { Comprising field study to } \\
\text { evaluate the usefulness, } \\
\text { applicability and usability. }\end{array}$ \\
\hline
\end{tabular}

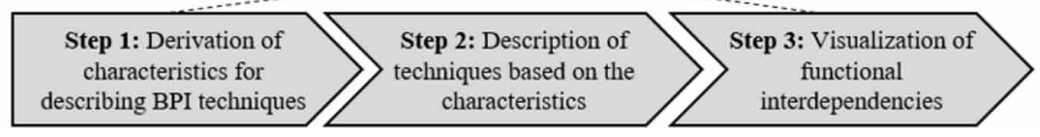

The problem statement was formulated in the introduction (Problem). Afterwards, requirements on our "map" (Objectives of a Solution) are derived and our design is described (Design \& Development). In this context, selected characteristics of BPI techniques to specify our set of techniques are used (see Table 1). The characteristics help to describe the BPI techniques in a structured way, so that similarities and differences become evident. Then, functional interdependencies are derived by considering the input and output information of the techniques. These interdependencies are visualized by using a graphical representation and, that way, the "map" of BPI techniques - called "Functional Interdependency Map" hereafter - emerges. By help of a laboratory experiment, the usability of the "Functional Interdependency Map" is demonstrated (Demonstration). In the future, the map will be subjected to a larger field study (cf. Gregor \& Hevner, 2013; Hevner et al., 2004). 


\section{Constructing the Functional Interdependency Map}

Before we describe the design of the map, we outline corresponding design requirements (see Figure 1 - "Objectives of a Solution").

\section{Design Requirements}

In literature, different requirements have been posed on the quality of conceptual models or graphical representations, respectively (e.g., Frank, 1998; Frank, 2011; Guceglioglu \& Demirors, 2005; Krogstie, 2015; John Krogstie et al., 1995; Overhage et al., 2012; Vanderfeesten et al., 2007). For the "Functional Interdependency Map", the following design requirements (DR) (cf. Hevner et al., 2004) - that were categorized into the dimensions "sematic", "syntactic" and "pragmatic" quality (Krogstie, 2015) - guided the design process (see Table 3).

Table 3. Design requirements

\begin{tabular}{|c|c|c|}
\hline \multicolumn{2}{|c|}{ Design Requirement (DR) } & Explanation \\
\hline \multirow[t]{2}{*}{ Syntax } & $\begin{array}{l}\text { DR 1: Existence of a } \\
\text { metamodel }\end{array}$ & $\begin{array}{l}\text { The modelling constructs as well as the allowed relations, and thus the } \\
\text { syntactical rules for creating the map, are specified by help of classes and } \\
\text { relations in a metamodel (cf. Frank, 2000; Karagiannis \& Höfferer, 2006; } \\
\text { Schütte \& Rotthowe, 1998). }\end{array}$ \\
\hline & $\begin{array}{l}\text { DR 2: Formalization } \\
\text { of the metamodel }\end{array}$ & $\begin{array}{l}\text { The metamodel (see DR 1) can be formalized to assure the uncovering of } \\
\text { inconsistencies, syntactical errors and incompleteness of the metamodel } \\
\text { design (cf. Fill et al., 2013; Frank, 2000; Frank \& Prasse, 1997; Fraser et al., } \\
\text { 1994). Moreover, the ground is prepared for an IT-based processing of model } \\
\text { instances. }\end{array}$ \\
\hline \multirow[t]{3}{*}{ Semantics } & $\begin{array}{l}\text { DR 3: } \\
\text { Expressiveness \& } \\
\text { extensibility }\end{array}$ & $\begin{array}{l}\text { The model visualizes the relevant knowledge (functional interdependencies/ } \\
\text { synergies between BPI techniques) sufficiently and can be extended if } \\
\text { required (by additional BPI techniques and relations) (cf. Frank \& Prasse, } \\
\text { 1997; Recker et al., 2011). }\end{array}$ \\
\hline & $\begin{array}{l}\text { DR 4: Adequacy } \\
\text { regarding purpose \& } \\
\text { minimality }\end{array}$ & $\begin{array}{l}\text { The model does not contain irrelevant information and no construct can be } \\
\text { removed without losing information (cf. Frank, 2000; Mendling et al., 2010; } \\
\text { Schütte \& Rotthowe, 1998). }\end{array}$ \\
\hline & DR 5: Verifiability & $\begin{array}{l}\text { The knowledge captured in the model can be assessed and verified by users } \\
\text { in BPI projects, which may also lead to enterprise-specific adaptions of the } \\
\text { map (cf. Frank, 2000; Krogstie, 2015; Krogsie et al., 1995). }\end{array}$ \\
\hline \multirow[t]{2}{*}{ Pragmatism } & $\begin{array}{l}\text { DR 6: Ease-of- } \\
\text { understanding and } \\
\text { learnability }\end{array}$ & $\begin{array}{l}\text { The map can be used in BPI projects straight away without additional } \\
\text { training efforts being required. Hence, it is self-explanatory at large (cf. } \\
\text { Krogstie, 2015; Krogstie et al., 2006; Overhage et al., 2012). }\end{array}$ \\
\hline & $\begin{array}{l}\text { DR 7: Uniqueness } \\
\text { of the abstract syntax } \\
\text { \& semantics }\end{array}$ & $\begin{array}{l}\text { Potential ambiguities within the model are reduced as far as possible (cf. } \\
\text { Frank, 2000). }\end{array}$ \\
\hline
\end{tabular}

To come to a map that fulfills the design principles regarding the "semantic" as well as "pragmatic" quality (DR 3 to DR 7) and outlines beneficial functional interdependencies (based on input-/outputrelationships) the authors of this study propose the following major modeling constructs to determine the design of the metamodel (DR 1 and DR 2): "BPI technique", "input/output (information)" and "relations". Thereby, each BPI technique requires one type of input information at least (e.g., chart, data, etc.) and produces one or more types of output information (e.g., document, graph, etc.).

It is important to mention that the information (input or output) can either represent tacit or explicit knowledge about the process (cf. Nonaka, 2007). While explicit knowledge is easy to communicate 
because it is captured in form of tables, sheets or specifications amongst others, tacit knowledge is personal and not coded in form of physical documents (e.g., know-how, ideas, etc.) (Nonaka, 2007). Figure 2 shows the metamodel of the "Functional Interdependency Map".

Figure 2. Metamodel of the Functional Interdependency Map

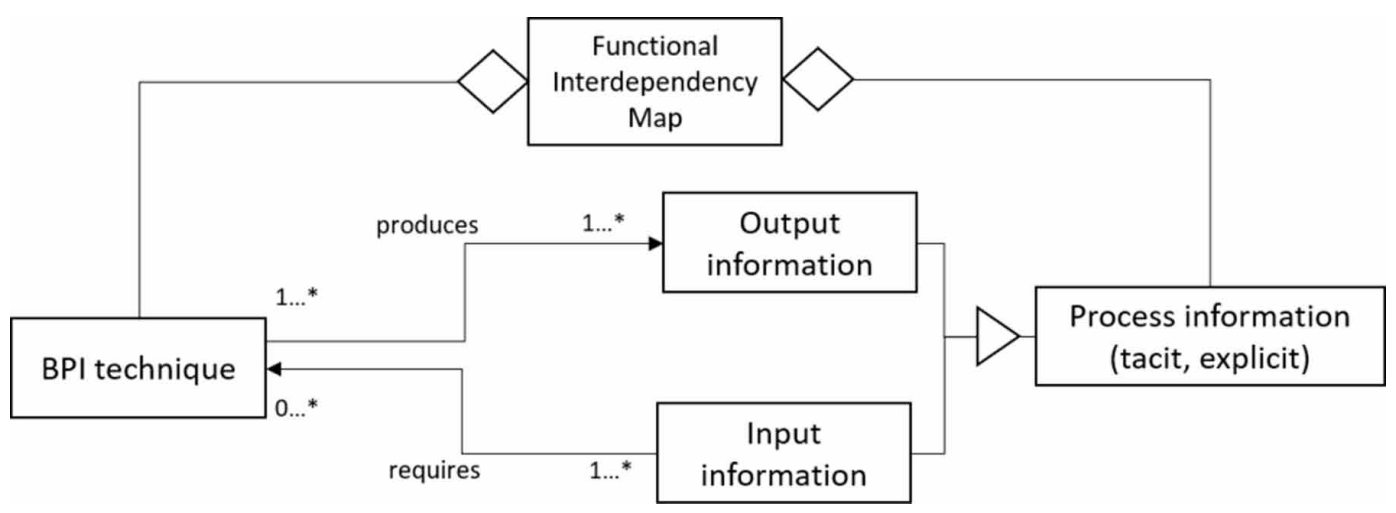

Moreover, an excerpt of its formalization via the FDMM (Formalism for Describing ADOxx Meta Models and Models) formalism (cf. Fill et al., 2012) is presented hereafter (DR 2). Thereby, formalization is helpful for uncovering inconsistencies, syntactical errors and incompleteness of the metamodel design (Fraser et al., 1994). Whereas various formalization approaches have been introduced for that purpose, such as EMOF (Favre, 2010) or KM3 (Jouault \& Bézivin, 2006), the focus of these approaches is on the specification of software architectures (Fill et al., 2013). Contrary, a generally valid formalization approach for domain independent metamodels is FDMM (Fill et al., 2012). FDMM is based on the set theory and first-order-logic, does not require advanced mathematical skills and is generally applicable across domains (Fill et al., 2012). Because of that, it was chosen for the study at hand:

FDMM excerpt for above shown metamodel:

$\mathrm{M}_{\mathrm{FIM}}^{\mathrm{T}}=<\mathrm{O}_{\mathrm{FIM}}^{\mathrm{T}}, \mathrm{D}_{\mathrm{FIM}}^{\mathrm{T}}, \mathrm{A}_{\mathrm{FIM}}>$

$\mathrm{O}_{\text {FIM }}^{\mathrm{T}}=\{\mathrm{BPI}$ technique, Output information, Input information,

Process information, produces, requires]

Output information $\leq$ Process information

Input information $\leq$ Process information 
As equation 1 shows (see example above), metamodels in FDMM are represented as a tuple of a set of object types ( $O_{i}^{T}$, data types ( $D_{i}^{T}$. and attributes ( $A_{j}$. (Fill et al., 2012). In our case, we define the model type "FIM", which stands for "Functional Interdependency Map". In equation 2, the object types of the metamodel are defined. Inheritance relationships are specified in equations 3 and 4. Hence, the object types "Output information" and "Input information" are subtypes of the object type "Process information". Further details about the FDMM formalism can be found in Fill et al. (2013) for instance. Regarding the study at hand, the formalization of the metamodel could be performed straightforward, which is an indicator for its completeness, consistency and syntactical correctness (e.g., Fraser et al., 1994).

\section{Design and Development}

For being able to identify functional interdependencies and to design the map, the BPI techniques from Table 1 were described by the author team using the characteristics "goal" (what is the purpose of the technique?), "input information" (what is needed for a technique's use?), "output information" (what is the outcome of the technique?) and "procedure" (how does the technique function?) at first. Based on the input information, output information and goal of a BPI technique, functional interdependencies in the sense of Bruhn (2019) can be determined. For that purpose, three raters (observers) read the descriptions of the BPI techniques given in literature, with respect to details about the four selected attributes (goal, input information, output information and procedure). The use of multiple raters was necessary because in content analysis, people (observers) are employed to systematically interpret the units of analysis (e.g., text), but "when relying on human observers, researchers must worry about the quality of the data - specifically, their reliability" (Hayes \& Krippendorff, 2007, p. 78). The observers need to agree on the data they generate to accomplish reliability (cf. Hayes \& Krippendorff, 2007). In our study, this was done by three researchers. That way, interrater agreement can be achieved, and the ratings of one observer are interchangeable with the ratings of another (Brutus et al., 1998). The following Table 4 shows the results of the systematic description exemplified for the BPI techniques "bureaucracy elimination" and "should-be process map". All BPI techniques listed in Table 1 have been described that way while only an excerpt is presented due to page restrictions. Table 4 then served as the basis for identifying functional interdependencies between the BPI techniques. Therefore, each of the three researchers analyzed the techniques in Table 4 regarding the following aspects: Which input information does a specific BPI technique require? As to what degree is this input information provided as output information by another technique? As to what degree can functional interdependencies between BPI techniques be established regarding input-output relations? Afterwards, the results of the researchers were compared, discussed and a final consensus was derived. Based on these findings, the metamodel (Figure 2) was instantiated and the "Functional Interdependency Map" created (Figure 3). ${ }^{1}$

Thereby, the BPI techniques are represented by conventional squares that are numbered in accordance with Table 1 (see Figure 3). Input respectively output information is symbolized by squares with shifted borders. The arrows indicate the flow of information; i.e., whether input information is required by a technique or output information produced accordingly. Hence, a labeling of the arrows is not necessary. For instance, it gets evident that the "as-is process flow chart" represents output information that can serve as input information for the BPI technique "process simplification (No. 24 in Table 1)". Figure 3 shows the BPI techniques that have been listed in Table 1 but due to reasons of demonstration only a certain excerpt from the figure is highlighted. Conditional or complementary interdependencies, respectively, get evident in the map in case an output information is produced by a BPI technique and serves as input information to another technique (see section "BPI Techniques \& Functional Interdependencies"). Both types of interdependencies build on associations between techniques that are determined by input-output relations. However, the difference between conditional or complementary interdependencies is not visualized in our map. This is because the judgement of 
whether a conditional or complementary interdependency is given largely depends on the process knowledge (cf. Amaravadi \& Lee, 2005) of employees. Take the BPI technique "process simplification" for instance (see Figure 3). An "as-is-process flow chart" undeniably is helpful to identify means to improve the process flow (cf. Harrington \& Lomax, 2000). However, for employees who are not familiar with the process under study the "as-is-process flow chart" is absolutely mandatory and hence, a conditional interdependency between the "flow chart" and the "process simplification" technique would be given. Contrary, employees that are well-familiar with the process may consider the "as-is-process flow chart" as a supplementary information material only and a complementary interdependency would be specified accordingly. Since "process knowledge" is a major factor for deciding whether a complementary or conditional interdependency exists and both interdependency types build on input-output relations in addition, there is no graphical differentiation for these in the map.

Substituting interdependencies (cf. Bruhn, 2019) become obvious in case two BPI techniques produce the same type of output information. For example, "bureaucracy elimination" (No. 5 in

Table 4. Evaluation of BPI techniques (excerpt)

\begin{tabular}{|c|c|c|c|c|c|}
\hline No. & Technique & Goal & Input information & $\begin{array}{c}\text { Output } \\
\text { information }\end{array}$ & Procedure \\
\hline 5 & $\begin{array}{l}\text { Bureaucracy } \\
\text { elimination }\end{array}$ & $\begin{array}{l}\text { - Identify } \\
\text { and eliminate } \\
\text { bureaucracy }\end{array}$ & $\begin{array}{l}\text { - Knowledge about } \\
\text { the process } \\
\text { - Knowledge about } \\
\text { (process-) problems } \\
\text { - Knowledge about } \\
\text { control structures } \\
\text { (who approves } \\
\text { someone else's } \\
\text { work?) } \\
\text { - Knowledge about } \\
\text { documentation of } \\
\text { activities (too many } \\
\text { copies) } \\
\text { - Flow chart } \\
\text { - Knowledge about } \\
\text { review, approval, } \\
\text { signing or inspection }\end{array}$ & $\begin{array}{l}\text { - List of } \\
\text { unnecessary } \\
\text { paper work } \\
\text { - List of } \\
\text { unnecessary } \\
\text { responsibilities } \\
\text { - List of } \\
\text { unnecessary } \\
\text { inspection } \\
\text { - "Lean" } \\
\text { processes } \\
\text { through the } \\
\text { elimination of } \\
\text { unnecessary } \\
\text { bureaucracy } \\
\text { within the } \\
\text { activities of a } \\
\text { process }\end{array}$ & $\begin{array}{l}\text { 1. Track down bureaucracy in } \\
\text { activities by asking questions like } \\
\text { "Are several copies stored for no } \\
\text { apparent reason?" } \\
\text { 2. Combine flow chart of the } \\
\text { process with the activities } \\
\text { constituting bureaucracy from } 1 \\
\text { by highlighting these } \\
\text { 3. The person responsible for } \\
\text { each of the "blue" activities is } \\
\text { asked to present an overview } \\
\text { of time and costs related to the } \\
\text { activity as well as its usefulness } \\
4 . \text { Activities that cannot be } \\
\text { justified in step } 3 \text { are eliminated }\end{array}$ \\
\hline$\cdots$ & $\cdots$ & $\cdots$ & $\cdots$ & $\cdots$ & $\cdots$ \\
\hline 30 & $\begin{array}{l}\text { Should-be } \\
\text { process map }\end{array}$ & $\begin{array}{l}\text { - Simplify } \\
\text { understanding } \\
\text { - Create shared } \\
\text { understanding } \\
\text { amongst the } \\
\text { team for the } \\
\text { problem } \\
\text { - Clarify the } \\
\text { individual } \\
\text { process steps } \\
\text { - Identify } \\
\text { the process } \\
\text { structure } \\
\text { - Clarify the } \\
\text { complexity }\end{array}$ & $\begin{array}{l}\text { - Activities to be } \\
\text { considered } \\
\text { - Causes of failure } \\
\text { - Improvement } \\
\text { actions }\end{array}$ & $\begin{array}{l}\text { Visualization of } \\
\text { a "should-be" } \\
\text { process }\end{array}$ & $\begin{array}{l}\text { 1. Define the start- and endpoint } \\
\text { of the process } \\
2 \text {. Define those activities that } \\
\text { should be considered by the } \\
\text { process } \\
\text { 3. Put the activities into a correct } \\
\text { sequence }\end{array}$ \\
\hline$\cdots$ & $\ldots$ & $\cdots$ & $\cdots$ & $\cdots$ & $\cdots$ \\
\hline
\end{tabular}




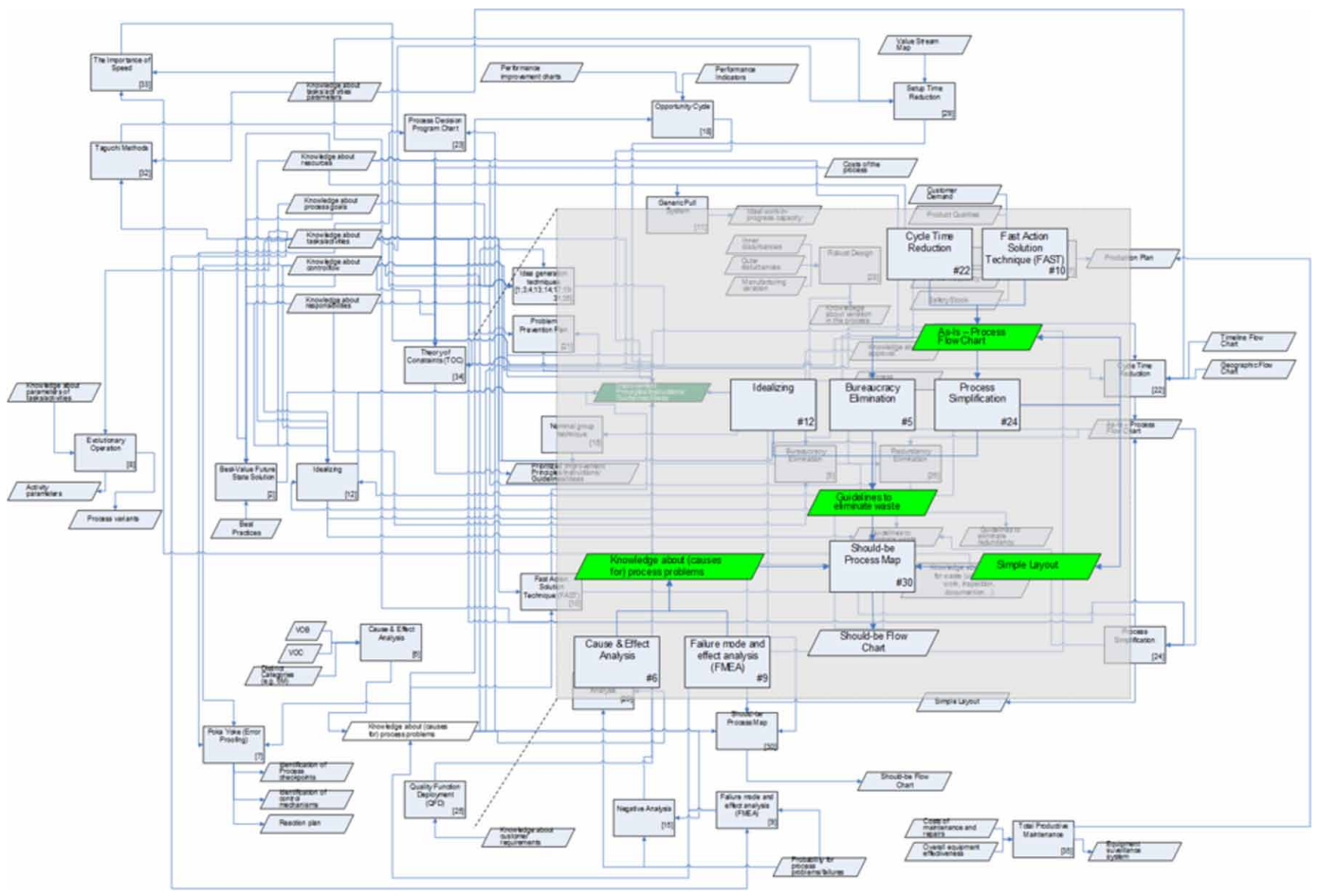

Table 1), "idealizing" (No. 12 in Table 1) and "process simplification" (No. 24 in Table 1) lead to the output information "guidelines to eliminate waste". Hence, substituting interdependencies are acknowledged. Rivalling interdependencies exist, in case the application of BPI techniques generates results that are contradictory to one another (Bruhn, 2019). According to Bruhn (2019), the danger of rivalling interdependencies is especially given if cost-oriented and customer-oriented results are strived for in a project at the same time. However, contradictory outcomes in a BPI project are usually caused by an inappropriate use of BPI techniques. In our map, rivalling interdependencies cannot be identified immediately. This is because this type of interdependency cannot be primarily explained by the nature of the BPI techniques but much more by their improper use. An indicator pointing at rivalling interdependencies is the use of common output information types for different BPI techniques, which is a circumstance similar to substituting interdependencies. In that case, the danger of producing identical types of output information (e.g., improvement ideas) is given, which however may be contradictory to one another. For instance, with "bureaucracy elimination (No. 5)" certain activities of a process (e.g., "customer inquiry analysis") may be eliminated, which - in turn - may be added again when using the technique "idealizing (No. 12)" to come to an idealistic process flow (see Figure 3).

\section{Example for Using the Map}

To demonstrate the application of the map in an example, we zoom in towards the technique "shouldbe process map (No. 30)" in Figure 3. "Should-be process maps" are often generated in an "ad-hoc" fashion in improvement projects. Therefore, they usually reflect the improvement ideas of individuals without considering the actual causes for unsatisfying process performance. Thus, the need to create "should-be process maps (No. 30)" that are not based on subjectivity is given in many BPI projects. Figure 3 shows as to what degree functional interdependencies with further techniques exist that are 
helpful at that point. These are techniques that produce an output information, which can be used as input information by the "should-be process map (No. 30)".

In that context, the "cause-and-effect analysis (No. 6)" is a well-established technique for analyzing the shortcomings of a business process. The insights gained from this analysis help in designing a "should-be process map (No. 30)" that avoids the problem causes of the as-is process. Results can even be more precise by using the "FMEA (No. 9)" (Failure Mode and Effects Analysis). By help of the FMEA, each activity of an as-is process is analyzed regarding potential defects that might occur during process execution. The effect of each failure, its severity, its frequency of occurrence as well as the probability to identify the failure is carefully investigated (cf. Meran et al., 2013). With this knowledge, appropriate solutions for avoiding process failures can be developed. Moreover, techniques like "idealizing (No. 12)", "bureaucracy elimination (No. 5)" as well as "process simplification (No. 24)" support the user in creating a "should-be process map (No. 30)" because they foster the finding of solutions to overcome process weaknesses, which can be integrated in the "should-be map" on the spot.

\section{EXPERIMENTAL RESULTS}

\section{Setting and Experiment Conduction}

The usability of the "Functional Interdependency Map for BPI" (see Figure 3) was demonstrated by help of a laboratory experiment (cf. Peffers et al., 2007; Wohlin et al., 2012). In total, 33 Bachelor degree students of Management Information Systems (MIS) at a German university took part in the experiment. Each student was attending a course "Business Process Management" dealing with the fundamentals of BPI. The case study - used for the experiment - was based on a real BPI project that was conducted by the authors of this study in cooperation with a financial service provider in the automobile industry and focused the document management process. The process works as follows: As soon as the customer mail is received it is sorted by the postal service of the automotive bank. Then, in the operational departments, the documents get pre-processed and are forwarded to the responsible employee. The employee creates a response for the customer, which is indexed and archived. After that, it is moved to the outbox folder.

For the case study, current problems of the process were unveiled in form of employee and customer statements. The participants were supposed to develop process improvement opportunities by help of BPI techniques from Table 1.

To rate the usability of the "Functional Interdependency Map" - and hence its suitability to support users during the "act of improvement" - we used an adapted version of the "System Usability Scale (SUS)" (Brooke, 1986). Generally, different approaches exist for performing usability ratings in the IS discipline (e.g., Software Usability Measurement Inventory (SUMI), ASQ (American Society for Quality) approach, etc.) (cf. Sauro \& Lewis, 2012). We chose SUS because its shortness (10 items) raises users' willingness to fill-out the questionnaire, the results are comprehensible for non-experts, the scale even works with a small sample size and it is judged to be an established and robust measurement system (Bangor et al., 2008; Orfanou et al., 2015; Tullis \& Stetson, 2004). The 10 items (statements) of the questionnaire ${ }^{2}$ cover aspects like the need for support, training or complexity, and thus, allow to reflect on the system from different angles ( $\mathrm{Ng}$ et al., 2011). Despite its shortness, research could show that the SUS results are highly valid (Lewis \& Sauro, 2009) and SUS was used for approx. $43 \%$ of post-test usability evaluations, which reinforces its wide acceptance (Sauro \& Lewis, 2009). More explanations about the SUS instrument are given in Brooke (1986) or Brooke (1996) for instance. An adaption of the 10 items-questionnaire for the study at hand can be viewed in the supplementary material to the experiment (https://tinyurl.com/y3wo3rwn) or the next section, respectively.

Besides the usability, also the perceived quality of the map - and hence the "model quality" was to be rated from the user perspective. Generally, the measurement of model quality is a lively discussed topic in literature and quality frameworks, metrics, empirical surveys as well as pragmatic 
guidelines were introduced in recent years (Avila et al., 2019; Mendling et al., 2010). These approaches build on quality dimensions such as complexity, modularity, size or cohesion to quantify conceptual model quality (Braunnagel et al., 2015; Vanderfeesten et al., 2007). Against this background, the "understandability" of a conceptual model has established as a commonly accepted quality criterion (Houy et al., 2012, 2014).

We therefore measured the "perceived ease of understanding (PEOU)" for our map in adaption of Maes \& Poels (2007). The PEOU rating determines as to what the degree it is possible to understand the problem domain modelled "free of mental efforts" (Maes \& Poels, 2007, p. 708). Research has shown that the PEOU positively influences users' perceived usefulness of a conceptual model as well as the general user satisfaction (Maes \& Poels, 2007). The determination of the PEOU measure is based on four items (Maes \& Poels, 2007). ${ }^{3}$ In our case, the PEOU measurement helped to assess whether the "Functional Interdependency Map" supported users in understanding the functional interdependencies between BPI techniques or not.

Accordingly, the questionnaire for our experiment comprised 14 items in total, which were to be rated by help of a 5-point Likert scale. The items came from the aforementioned SUS questionnaire and the PEOU measurement scale (cf. Brooke, 1996; Maes \& Poels, 2007). The case study and the questionnaire can be accessed at: https://tinyurl.com/y3wo3rwn

Before conducting the experiment, the students received an introduction to BPI in abovementioned course "Business Process Management". Since the set of BPI techniques that is used in companies usually is limited, we narrowed the scope and selected a set of seven techniques from Table 1 (bureaucracy elimination, cause and effects analysis, cycle time reduction, fast action solution technique, FMEA, idealizing, simplification) to be referred to for developing improvement suggestions in the case study. We created a one-page tutorial for each BPI technique as mentioned, which indicated how to work with the technique. Then, the students were handed-out the description of the document management process - along with the instruction to create improvement suggestions -, the "Functional Interdependency Map", the quick tutorial for each BPI technique as well as the questionnaire. Students were asked to use the "Functional Interdependency Map" as a reference for selecting BPI techniques to structure the "act of improvement". Principally, the participants were free in their choice of BPI techniques. The students were supposed to solve the case study on their own, which was supervised by the course instructor. In total, a timeframe of 90 minutes was set for the case study. Afterwards, students were supposed to fill-out the questionnaire and we received 33 completed questionnaires from all participants (100\%), which also is an indicator for the high practicality of the measurement scales used. The data was analyzed by help of the freely available statistics software " $\mathrm{R}$ " (https:// www.r-project.org/).

\section{Results}

Figure 4 shows the results of the experiment regarding the perceived ease of understanding of the map (PEOU 1 to PEOU 4). ${ }^{4}$ For each item, the corresponding data distribution in form of a boxplot is shown. Obviously, the map enabled participants to understand the beneficial interdependencies between BPI techniques (PEOU 1) and it was perceived as easy to read at the same time (PEOU 4). Generally, only very few participants claimed to be overstrained by using the map (PEOU 2), while most students quickly figured out how to work with it (PEOU 3).

In Figure 5, the results from the usability assessment on base of the adapted SUS approach are shown. ${ }^{5}$ In this regard, the usability was confirmed by the experiment participants at large and the "Functional Interdependency Map" was judged to be helpful for solving the case study (items 1 to 5 , 8 and 9). Moreover, participants found it easy to work with the map (item 3). However, few students had some problems in understanding that a certain BPI technique was associated with more than one type of input or output information respectively (item 6). Finally, some participants stated that advanced knowledge on BPI would be helpful for using the map (item 10). Though, the majority believed the map to be supportive even for novices in the BPI field (item 7). 


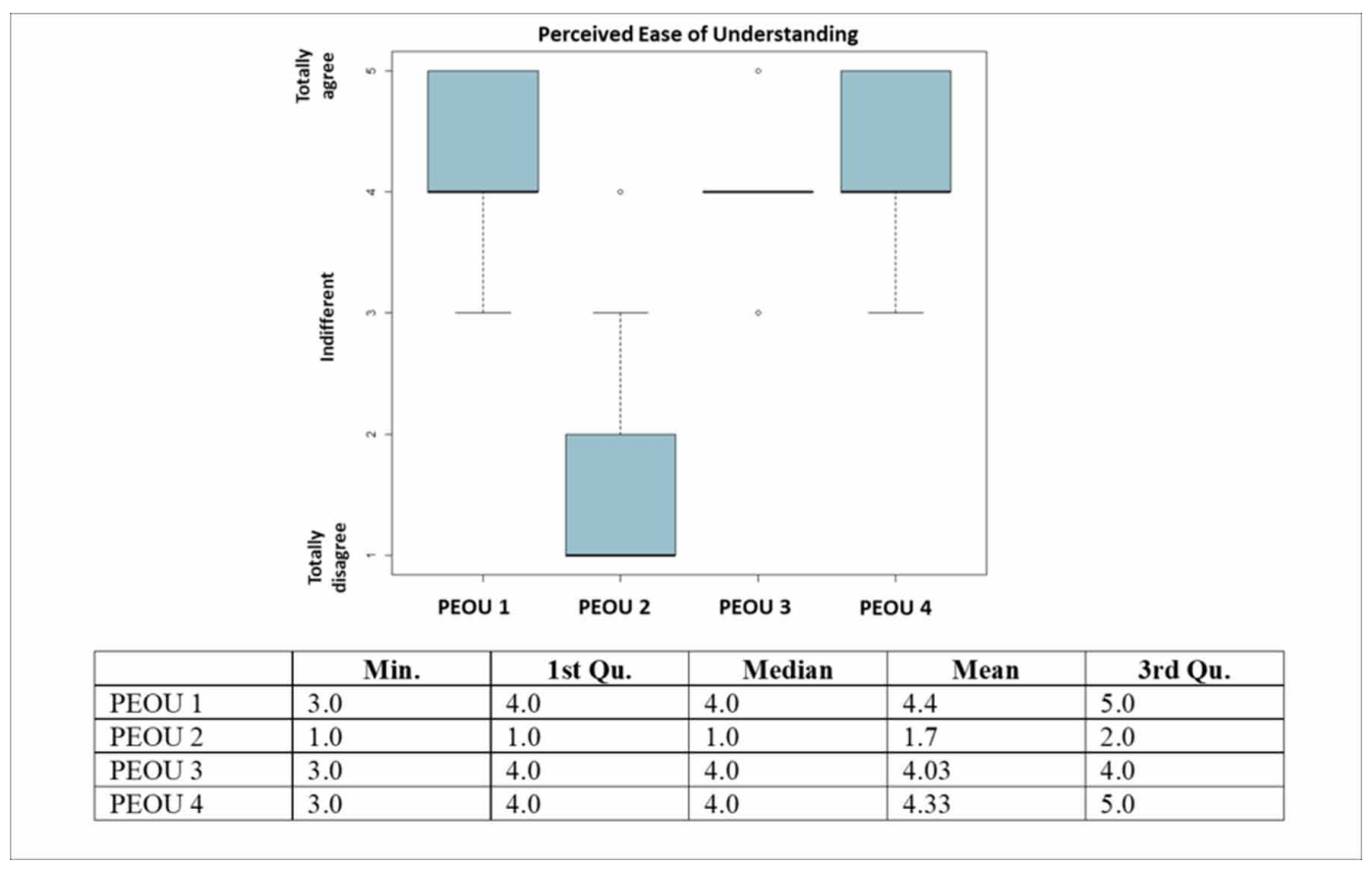

\section{BENEFITS AND DISCUSSION}

The research holds benefits for research and practice alike.

\section{Benefits for Research}

At first, an approach to easily visualize functional interdependencies between BPI techniques by help of a graphical map and to support the "act of improvement" was introduced. The functional interdependencies between BPI techniques are specified via the input information processed as well as output information generated. By that, particular weaknesses of certain BPI techniques can be mitigated (e.g., subjectivity) by proposing other techniques to be used in addition. So, if the input information for applying a technique is not available or based on pure assumptions, the results achieved may be flawed. ${ }^{6}$ In case the required information to mitigate such problems can be provided by another technique, a beneficial combination of these BPI techniques is given. Hence, researchers dealing with the further development of BPI techniques may focus on the relations between input information and output information across techniques to find ways to eliminate a technique's weak points by the use of additional techniques.

Second, the map unveils fruitful combinations of techniques that support the "act of improvement" in particular, which - to the best of our knowledge - have not been uncovered in such detail in the BPI literature yet. That is because BPI is described to be an "art" rather than science (Davenport, 2005; Hall \& Johnson, 2009) and creativity still is a major part during the improvement process. Whereas selected fruitful combinations of BPI techniques are dealt with in literature (e.g., Shen et al., 2000; Tontini, 2007), the "big picture", which techniques may provide valuable input information for other BPI techniques, is missing. Thereby, the map reveals promising combinations for a set of 36 techniques with a multitude of constellations that have not been subject of investigation yet.

Third, the map supports the construction of an enterprise-adapted "roadmap" (cf. Mirbel \& Ralyté, 2006), which can be seen as a logical arrangement of BPI techniques to be used for improving 


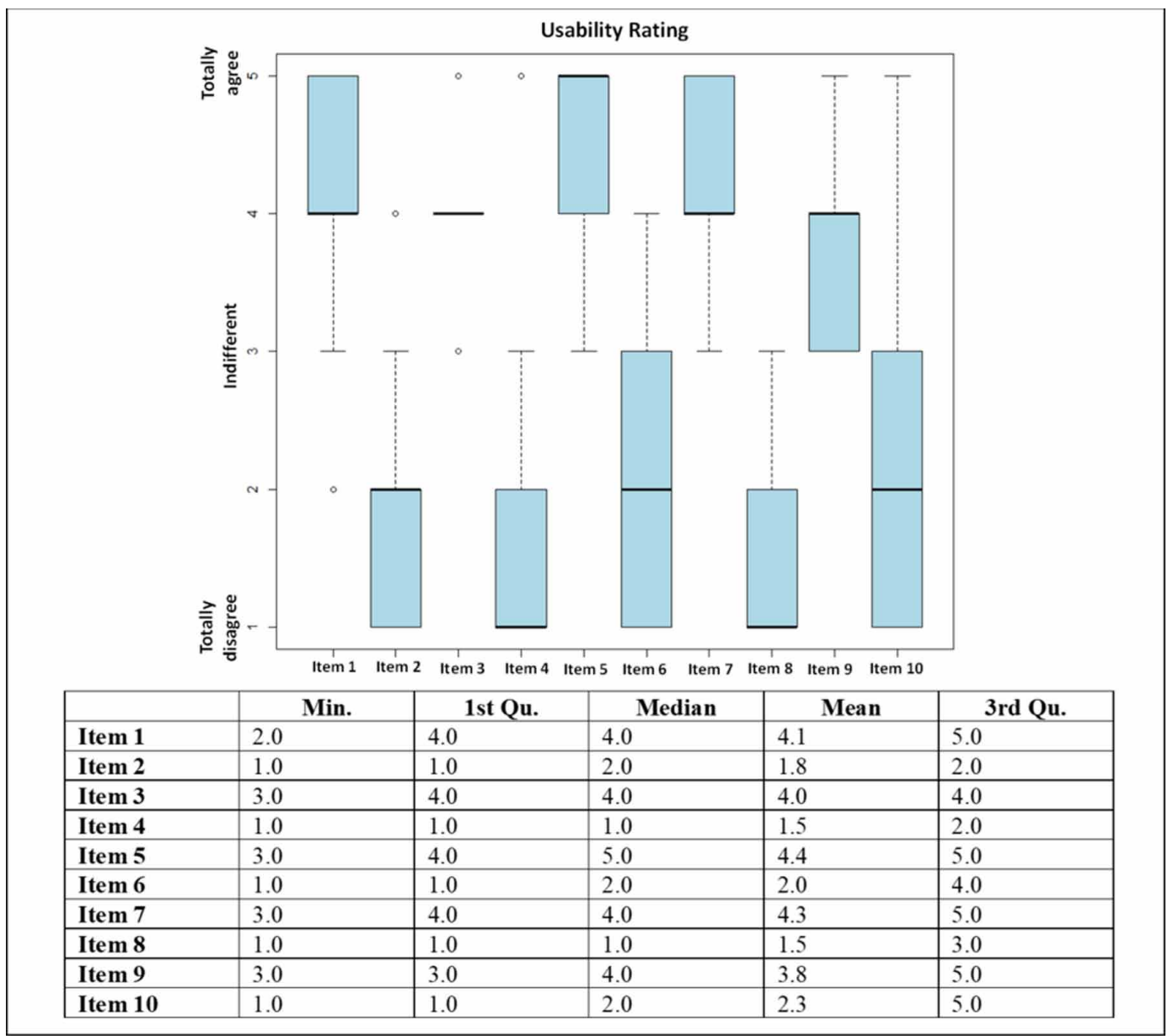

a business process. Thereby, the user defines the output information (results) strived for and searches for corresponding BPI techniques to provide these. Based on the map, combinations of techniques to generate the aspired outcomes can then be identified.

\section{Benefits for Practice}

Besides academia, the research is also beneficial for practice. At first, the map is a helpful means to support a practitioner in selecting BPI techniques for a project. It provides an overview of wellestablished BPI techniques users may chose for their project and outlines, which input information is needed for a proper application of each technique. If the information is not directly available (e.g., customer requirements are unknown) another technique from the map should be selected or the application of BPI techniques providing this type of input information considered. Otherwise, the use of the technique is based on assumptions (e.g., regarding customer expectations) that might not reflect the real-world situation, delivering flawed results in the end (e.g., Tontini, 2007). The map is helpful in that context since it shows, which BPI techniques provide the input information needed by another technique as output information. Although BPI techniques have the same major goal (to improve a process) they differ regarding the input information they process. Thus, the map supports a 
practitioner to choose BPI techniques for which the information is available straightaway in a project or to select additional BPI techniques to provide this input.

Second, a practitioner may refer to the map in case the application of particular techniques in BPI projects turns out to be challenging due to a lack of input information (e.g., Tan \& Pawitra, 2001) or the results from the technique's application stay beyond expectations. In the latter case, wrong assumptions may have been used when working with the technique or information processed may have been imprinted by employees' subjective perceptions (e.g., regarding the severity of problem causes). Accordingly, the map gives hints, which additional techniques may be used to specify or generate the required information, and hence, to overcome problems stemming from a processing of inaccurate information.

\section{Limitations}

The research also has limitations. At first, the investigation is restricted to a set of 36 BPI techniques according to Griesberger et al. (2011). These techniques focus on the "act of improvement" in particular and do not cover phases before and after this step (e.g., phases "project definition"). Although Figure 3 represents the consensus of three researchers, subjectivity cannot be completely eliminated. This is especially true, since some enterprises may have developed proprietary modifications of certain techniques so that the input information, output information and procedure may differ from the one shown in Table 4. Nevertheless, the description of the techniques (see Table 4) is based on existing literature to reach general validity. In addition, the focus is on input-output relationships to describe the functional interdependencies between the BPI techniques. This is due to the major focus on complementary and conditional interdependencies in the sense of Bruhn (2019) that make up beneficial synergies between BPI techniques. Finally, a comprising evaluation of the approach at various companies of different size is an open topic yet (see Figure 1 - "Evaluation \& Communication").

\section{CONCLUSION}

In the work at hand, a map to show beneficial functional interdependencies between BPI techniques is designed that helps users in performing the "act of improvement" in a systematic way. In further research, it is intended to build "roadmaps" of BPI techniques for different improvement projects that are characterized by certain project characteristics. More, the influence of the project situation on the selection of techniques needs to be analysed in more detail. Thus, it is intended to use the map in real world situations to get more feedback on combinations of BPI techniques, which employees prefer considering certain project situations. 


\section{REFERENCES}

Acatech. (2016). Smart Service Welt: Digitale Serviceplattformen - Praxiserfahrungen aus der Industrie - Best Practices. https://www.acatech.de/publikation/smart-service-welt-digitale-serviceplattformen-praxiserfahrungenaus-der-industrie-best-practices/

Adesola, S., \& Baines, T. (2005). Developing and evaluating a methodology for business process improvement. Business Process Management Journal, 11(1), 37-46. doi:10.1108/14637150510578719

Aikhuele, D., \& Turan, F. (2018). A conceptual model for the implementation of lean product development. International Journal of Service Science, Management, Engineering, and Technology, 9(1), 1-9. doi:10.4018/ IJSSMET.2018010101

Akao, Y. (1990). QFD: Integrating Customer Requirements into Product Design. Productivity Press.

Al-Hudhaif, S. A. (2009). Process redesign: Reengineering core process at computer department-a case of SWCC. Business Process Management Journal, 15(2), 184-200. doi:10.1108/14637150910949443

Amaravadi, C. S., \& Lee, I. (2005). The dimensions of process knowledge. Knowledge and Process Management, 12(1), 65-76. doi:10.1002/kpm.218

Anaby-Tavor, A., Amid, D., Fisher, A., Bercovici, A., Ossher, H., Callery, M., \& Simmonds, I. (2010). Insights into enterprise conceptual modeling. Data \& Knowledge Engineering, 69(12), 1302-1318. doi:10.1016/j. datak.2010.10.003

Andersen, B. (1999). Business process improvement toolbox. ASQ Quality Press.

Antony, J. (2006). Six sigma for service processes. Business Process Management Journal, 12(2), 234-248. doi: $10.1108 / 14637150610657558$

Avila, D. T., Cigana, R. P., Fantinato, M., Reijers, H. A., Mendling, J., \& Thom, L. H. (2019). An Experiment to Analyze the Use of Process Modeling Guidelines to Create High-Quality Process Models. Paper presented at the International Conference on Database and Expert Systems Applications. doi:10.1007/978-3-030-27618-8_10

Baines, A. (1996). Re-engineering revisited. Work Study, 45(3), 21-23. doi:10.1108/00438029610115497

Bangor, A., Kortum, P. T., \& Miller, J. T. (2008). An empirical evaluation of the system usability scale. International Journal of Human-Computer Interaction, 24(6), 574-594. doi:10.1080/10447310802205776

Beatson, A., Lee, N., \& Coote, L. V. (2007). Self-service technology and the service encounter. Service Industries Journal, 27(1), 75-89. doi:10.1080/02642060601038700

Belkeziz, R., \& Jarir, Z. (2020). An Overview of the IoT Coordination Challenge. International Journal of Service Science, Management, Engineering, and Technology, 11(1), 99-115. doi:10.4018/IJSSMET.2020010107

Bicheno, J. (2008). The lean toolbox for service systems. PICSIE Books.

Bouranta, N., Psomas, E., Suárez-Barraza, M. F., \& Jaca, C. (2019). The key factors of total quality management in the service sector: A cross-cultural study. Benchmarking, 26(3), 893-921. doi:10.1108/BIJ-09-2017-0240

Braunnagel, D., Johannsen, F., \& Leist, S. (2015). Analysing the contribution of coupling metrics for the development and management of process architectures. Paper presented at the Twenty-Third European Conference on Information Systems (ECIS), Münster.

Breyfogle, F., Cupello, J., \& Meadows, B. (2001). Managing Six Sigma. Wiley-Interscience.

Brooke, J. (1986). System usability scale (SUS): A quick-and-dirty method of system evaluation user information. Reading, UK: Digital Equipment Co Ltd.

Brooke, J. (1996). A quick and dirty usability scale. Usability evaluation in industry. Academic Press.

Bruhn, M. (2019). Operative Gestaltung des Qualitätsmanagements für Dienstleistungen. In M. Bruhn (Ed.), Qualitätsmanagement für Dienstleistungen (11th ed., pp. 309-418). Springer. doi:10.1007/978-3-662-59646-3_8 
Brutus, S., Fleenor, J. W., \& London, M. (1998). Does 360-degree feedback work in different industries? A between-industry comparison of the reliability and validity of multi-source performance ratings. Journal of Management Development, 17(3), 177-190. doi:10.1108/EUM0000000004487

Charles, A. (2017). PEX Network Annual Report 2017: Global state of process excellence. https://www. processexcellencenetwork.com/business-transformation/whitepapers/pex-network-annual-report-2017-globalstate-of

Dalmaris, P., Tsui, E., Hall, B., \& Smith, B. (2007). A framework for the improvement of knowledge-intensive business processes. Business Process Management Journal, 13(2), 279-305. doi:10.1108/14637150710740509

Davenport, T. H. (2005). Thinking for a Living: How to Get Better Performances and Results from Knowledge Workers. Harvard Business School Press.

Davenport, T. H., \& Short, J. E. (1990). The New Industrial Engineering: Information Technology and Business Process Redesign. Sloan Management Review, 31(4), 11-27.

Deming, W. E. (2000). Out of the crisis. MIT Press.

Falk, T., Griesberger, P., \& Leist, S. (2013). Patterns as an artifact for business process improvement-insights from a case study. In J. vom Brocke, R. Hekkala, M. Rossi, \& S. Ram (Eds.), Design Science at the Intersection of Physical and Virtual Design (pp. 88-104). Springer. doi:10.1007/978-3-642-38827-9_7

Favre, L. M. (2010). Formalization of MOF-Based Metamodels. In L. M. Favre (Ed.), Model Driven Architecture for Reverse Engineering Technologies (pp. 49-79). Information Resources Management Association. doi:10.4018/978-1-61520-649-0.ch004

Fill, H.-G., Hickl, S., Karagiannis, D., Oberweis, A., \& Schoknecht, A. (2013). A Formal Specification of the Horus Modeling Language Using FDMM. Proceedings 11th Wirtschaftsinformatik, 2.

Fill, H.-G., Redmond, T., \& Karagiannis, D. (2012). FDMM: A Formalism for Describing ADOxx Meta Models and Models. Paper presented at the ICEIS 2012, Poland.

Fill, H.-G., Redmond, T., \& Karagiannis, D. (2013). Formalizing Meta Models with FDMM: The ADOxx Case. In J. Cordeiro, L. A. Maciaszek, \& J. Filipe (Eds.), Enterprise Information Systems (Vol. 141, pp. 429-451). Springer. doi:10.1007/978-3-642-40654-6_26

Forster, F. (2006). The Idea behind Business Process Improvement: Toward a Business Process Improvement Pattern Framework. BPTrends, 1-13.

Frank, U. (1998). Evaluating Modelling Languages: Relevant Issues, Epistemological Challenges and a Preliminary Research Framework. https://www.wi.wiwi.uni-due.de/home/

Frank, U. (2000). Modelle als Evaluationsobjekt: Einführung und Grundlegung. Evaluation und Evaluationsforschung in der Wirtschaftsinformatik-Handbuch für Praxis, Lehre und Forschung.

Frank, U. (2011). Some Guidelines for the Conception of Domain-Specific Modelling Languages. Paper presented at the EMISA 2011.

Frank, U., \& Prasse, M. (1997). Ein Bezugsrahmen zur Beurteilung objektorientierter Modellierungssprachen - veranschaulicht am Beispiel von OML und UML. Arbeitsberichte des Instituts für Wirtschaftsinformatk, 6.

Fraser, M. D., Kumar, K., \& Vaishnavi, V. K. (1994). Strategies for incorporating formal specifications in software development. Communications of the ACM, 37(10), 74-86. doi:10.1145/194313.194399

Galli, B. J. (2018a). A Research Study on How Project Management Can Help Improve Lean Six Sigma: A Proposed Approach. International Journal of Service Science, Management, Engineering, and Technology, 9(4), 1-25. doi:10.4018/IJSSMET.2018100101

Galli, B. J. (2018b). Risks related to lean six sigma deployment and sustainment risks: How project management can help. International Journal of Service Science, Management, Engineering, and Technology, 9(3), 82-105. doi:10.4018/IJSSMET.2018070106 
Galli, B. J. (2020). Impact and Role of Motivation Theories in Continuous Improvement Environments: A Reflection of Literature. International Journal of Service Science, Management, Engineering, and Technology, 11(1), 1-13. doi:10.4018/IJSSMET.2020010101

Gimpel, H., Hosseini, S., Huber, R., Probst, L., Röglinger, M., \& Faisst, U. (2018). Structuring digital transformation: A framework of action fields and its application at ZEISS. Journal of Information Technology Theory and Application, 19(1), 31-54.

Gimpel, H., \& Röglinger, M. (2015). Digital Transformation: Changes and Chances - Insights based on an Empirical Study. https://fim-rc.de/wp-content/uploads/2020/02/Fraunhofer-Studie_Digitale-Transformation.pdf

Gisi, P. J. (2018). Sustaining a culture of process control and continuous improvement: The roadmap for efficiency and operational excellence. Taylor \& Francis.

Gregor, S., \& Hevner, A. R. (2013). Positioning and presenting design science research for maximum impact. Management Information Systems Quarterly, 37(2), 337-356. doi:10.25300/MISQ/2013/37.2.01

Griesberger, P., Leist, S., \& Zellner, G. (2011). Analysis of Techniques for Business Process Improvement. Paper presented at the 19th European Conference on Information Systems (ECIS 2011), Helsinki, Finland.

Grünberg, T. (2003). A review of improvement methods in manufacturing operations. Work Study, 52(2), 89-93. doi: $10.1108 / 00438020310462890$

Guceglioglu, A. S., \& Demirors, O. (2005). Using Software Quality Characteristics to Measure Business Process Quality. Lecture Notes in Computer Science, 3649, 374-379. doi:10.1007/11538394_26

Gutzwiller, T. A. (1994). Das CC RIM-Referenzmodell für den Entwurf von betrieblichen, transaktionsorientierten Informationssystemen. Physica-Verlag. doi:10.1007/978-3-642-52405-9

Hagemeyer, C., Gershenson, J. K., \& Johnson, D. M. (2006). Classification and application of problem solving quality tools: A manufacturing case study. The TQM Magazine, 18(5), 455-483. doi:10.1108/09544780610685458

Hall, J. M., \& Johnson, D. M. (2009). When should a process be art, not science? Harvard Business Review, $87(3), 58-65$.

Hall, M. (2006). Knowledge management and the limits of knowledge codification. Journal of Knowledge Management, 10(3), 117-126. doi:10.1108/13673270610670894

Hammer, M. (1990). Reengineering Work: Don't Automate-Obliterate. Harvard Business Review, 68(4), $104-111$.

Hänisch, T. (2017). Grundlagen Industrie 4.0. In V. Andelfinger \& T. Hänisch (Eds.), Industrie 4.0 (pp. 9-31). Springer. doi:10.1007/978-3-658-15557-5_2

Harmon, P., \& Garcia, J. (2020). The State of Business Process Management - 2020. https://www.bptrends.com/ bptrends-state-of-business-process-management-2020-report/

Harrington, H. J. (1991). Business Process Improvement - The Breakthrough Strategy for Total Quality, Productivity and Competiveness. McGraw-Hill.

Harrington, H. J., \& Lomax, K. C. (2000). Performance Improvement Methods: Fighting the War on Waste. McGraw-Hill.

Hayes, A. F., \& Krippendorff, K. (2007). Answering the Call for a Standard Reliability Measure for Coding Data. Communication Methods and Measures, 1(1), 77-89. doi:10.1080/19312450709336664

Herterich, M., Uebernickel, F., \& Brenner, W. (2015). Nutzenpotentiale cyber-physischer Systeme für industrielle Dienstleistungen 4.0. HMD Praxis der Wirtschaftsinformatik, 52(5), 665-680. doi:10.1365/s40702-015-0164-y

Hevner, A. R., March, S. T., Park, J., \& Ram, S. (2004). Design Science in Information Systems Research. Management Information Systems Quarterly, 28(1), 75-105. doi:10.2307/25148625

Houy, C., Fettke, P., \& Loos, P. (2012). Understanding Understandability of Conceptual Models - What Are We Actually Talking about? Lecture Notes in Computer Science, 7532, 64-77. doi:10.1007/978-3-642-34002-4_5

Houy, C., Fettke, P., \& Loos, P. (2014). On the theoretical foundations of research into the understandability of business process models. Paper presented at the European Conference on Information Systems 2014, Tel-Aviv. 
Imai, M. (1986). IKaizen: The Key to Japan's Competitive Success. McGraw-Hill.

Johannsen, F. (2017). Functional Interdependencies between Quality Techniques reverting to Meta Models. Paper presented at the "Wirtschaftsinformatik" Conference, St. Gallen.

Johannsen, F., \& Leist, S. (2009). Evaluation ausgewählter Qualitätstechniken in Six-Sigma-Projekten. In J. Moormann, D. Heckl, \& H. Lamberti (Eds.), Six Sigma in der Finanzbranche (pp. 361-379). Frankfurt School Verlag.

Johannsen, F., Leist, S., \& Zellner, G. (2015). Implementing Six Sigma for Improving Business Processes at an Automotive Bank. In J. vom Brocke \& M. Rosemann (Eds.), Handbook on Business Process Management 1 (2nd ed., pp. 361-382). Springer. doi:10.1007/978-3-642-45100-3_17

Johnston, G. (2012). Business process reengineering: A simple process improvement approach to improve business performance. The Business Productivity Series Book.

Jouault, F., \& Bézivin, J. (2006). KM3: a DSL for Metamodel Specification. Paper presented at the International Conference on Formal Methods for Open Object-Based Distributed Systems. doi:10.1007/11768869_14

Kanji, G. K., \& Asher, M. (1996). 100 Methods for Total Quality Management. Sage Publications. doi: $10.4135 / 9781446280164$

Kaplan, R. B., \& Murdock, L. (1991). Core process redesign. The McKinsey Quarterly, 28(2), 27-43.

Karagiannis, D., \& Höfferer, P. (2006). Metamodels in Action: An Overview. Paper presented at the ICSOFT 2006 - First International Conference on Software and Data Technologies, Setúbal.

Kettinger, W. J., Teng, J. T. C., \& Guha, S. (1997). Business process change: A study of methodologies, techniques, and tools. Management Information Systems Quarterly, 21(1), 55-80. doi:10.2307/249742

Kettler, N., Soffer, P., \& Hadar, I. (2019). Towards a Knowledge Base of Business Process Redesign: Forming the Structure. In Enterprise, Business-Process and Information Systems Modeling (pp. 3-18). Springer.

Kinnunen, S.-K., Ylä-Kujala, A., Marttonen-Arola, S., Kärri, T., \& Baglee, D. (2018). Internet of things in asset management: Insights from industrial professionals and academia. International Journal of Service Science, Management, Engineering, and Technology, 9(2), 104-119. doi:10.4018/IJSSMET.2018040105

Knorr, C., \& Friedrich, A. (2016). QFD-Quality Function Deployment: Mit System zu marktattraktiven Produkten. Carl Hanser Verlag GmbH Co KG. doi:10.3139/9783446449831

Krogstie, J. (2015). Capturing enterprise data integration challenges using a semiotic data quality framework. Business \& Information Systems Engineering, 57(1), 27-36. doi:10.1007/s12599-014-0365-X

Krogstie, J., Lindland, O. I., \& Sindre, G. (1995). Defining quality aspects for conceptual models. Paper presented at the IFIP international working conference on Information system concepts. doi:10.1007/978-0-387-34870-4_22

Krogstie, J., Lindland, O. I., \& Sindre, G. (1995). Towards a Deeper Understanding of Quality in Requirements Engineering. Proceedings of the 7th Conference on Advanced Information Systems Engineering (CaiSE '95). doi:10.1007/3-540-59498-1_239

Krogstie, J., Sindre, G., \& Jørgensen, H. (2006). Process models representing knowledge for action: A revised quality framework. European Journal of Information Systems, 15(1), 91-102. doi:10.1057/palgrave.ejis.3000598

Lang, M., Wehner, B., Falk, T., Griesberger, P., \& Leist, S. (2015). Evaluating Business Process Improvement Patterns by Simulation. Paper presented at the 23rd European Conference on Information Systems (ECIS 2015), Münster.

Lewis, J. R., \& Sauro, J. (2009). The factor structure of the system usability scale. Paper presented at the International conference on human centered design. doi:10.1007/978-3-642-02806-9_12

Maes, A., \& Poels, G. (2007). Evaluating quality of conceptual modelling scripts based on user perceptions. Data \& Knowledge Engineering, 63(3), 701-724. doi:10.1016/j.datak.2007.04.008

Magnusson, K., Kroslid, D., \& Bergman, B. (2004). Six Sigma the pragmatic approach. Professional Pub Serv. 
McQuater, R. E., Scurr, C. H., Dale, B. G., \& Hillmann, P. G. (1995). Using quality tools and techniques successfully. The TQM Magazine, 7(6), 37-42. doi:10.1108/09544789510103761

Mendling, J., Reijers, H., \& van der Aalst, W. (2010). Seven process modeling guidelines. Information and Software Technology, 52(2), 127-136. doi:10.1016/j.infsof.2009.08.004

Meran, R., John, A., Roenpage, O., \& Staudter, C. (2013). Six Sigma+Lean Toolset. Springer.

Mirbel, I., \& Ralyté, J. (2006). Situational method engineering: Combining assembly-based and roadmap-driven approaches. Requirements Engineering, 11(1), 58-78. doi:10.1007/s00766-005-0019-0

Ng, A. W., Lo, H., \& Chan, A. (2011). Measuring the Usability of Safety Signs: A use of system usability scale (SUS). Proceedings of the International MultiConference of Engineers and Computer Scientists.

Noh, H., Song, Y., Park, A.-S., Yoon, B., \& Lee, S. (2016). Development of new technology-based services. Service Industries Journal, 36(5-6), 200-222. doi:10.1080/02642069.2016.1165673

Nonaka, I. (2007). The knowledge-creating company. Harvard Business Review, 85(7-8), 162-171.

Nwabueze, U. (2012). Process improvement: The case of a drugs manufacturing company. Business Process Management Journal, 18(4), 576-584. doi:10.1108/14637151211253738

Okes, D. (2002). Organize Your Quality Tool Belt. Quality Progress, 82-86.

Orfanou, K., Tselios, N., \& Katsanos, C. (2015). Perceived usability evaluation of learning management systems: Empirical evaluation of the System Usability Scale. The International Review of Research in Open and Distributed Learning, 16(2), 227-246. doi:10.19173/irrodl.v16i2.1955

Österle, H. (1995). Business in the information age. Springer. doi:10.1007/978-3-662-03086-8

Overhage, S., Birkmeier, D. Q., \& Schlauderer, S. (2012). Quality Marks, Metrics, and Measurement Procedures for Business Process Models: The 3QM-Framework. Business \& Information Systems Engineering, 4(5), 229-246. doi:10.1007/s12599-012-0230-8

Pacicco, L., Ravarini, A., \& Pigni, F. (2010). Business Process Modelling within the Lifecycle of Continous Improvement. In A. D’Atri \& D. Sacca (Eds.), Information Systems: People, Organizations, Institutions, and Technologies (pp. 91-99). Physica-Verlag HD.

Page, S. (2015). The power of business process improvement: 10 simple steps to increase effectiveness, efficiency, and adaptability. AMACOM.

Pande, P., Neuman, R., \& Cavanagh, R. (2014). The Six Sigma Way: How to maximize the impact of your change and improvement efforts. McGraw Hill Professional.

Pande, P., Neumann, R., \& Cavanagh, R. (2000). The Six Sigma Way - How GE, Motorola and other top companies are honing their performance. Mc Graw Hill.

Peffers, K., Tuunanen, T., Rothenberger, M., \& Chatterjee, S. (2007). A Design Science Research Methodology for Information Systems Research. Journal of Management Information Systems, 24(3), 45-77. doi:10.2753/ MIS0742-1222240302

Pöppelbuß, J. (2018). Smart Service. Enzyklopaedie der Wirtschaftsinformatik - Online Lexikon.

Rahpeyma, B., \& Zarei, M. (2018). An integrated QFD-TOPSIS approach for supplier selection under fuzzy environment: A case of detergent manufacturing industry. International Journal of Service Science, Management, Engineering, and Technology, 9(3), 62-81. doi:10.4018/IJSSMET.2018070105

Ramaswamy, R., Reed, J., Livesley, N., Boguslavsky, V., Garcia-Elorrio, E., Sax, S., \& Parry, G. (2018). Unpacking the black box of improvement. International Journal for Quality in Health Care, 30(suppl_1), 15-19. doi:10.1093/intqhe/mzy009 PMID:29462325

Rath \& Strong. (2002). Six Sigma Pocket Guide. Rath \& Strong.

Recker, J., Rosemann, M., Green, P., \& Indulska, M. (2011). Do Ontological Deficiencies In Modeling Grammars Matter? Management Information Systems Quarterly, 35(1), 57-79. doi:10.2307/23043489 
Reijers, H. A., \& Limam Mansar, S. (2005). Best practices in business process redesign: An overview and qualitative evaluation of successful redesign heuristics. Omega, 33(4), 283-306. doi:10.1016/j.omega.2004.04.012

Sauro, J., \& Lewis, J. R. (2009). Correlations among prototypical usability metrics: evidence for the construct of usability. Proceedings of the SIGCHI conference on human factors in computing systems. doi:10.1145/1518701.1518947

Sauro, J., \& Lewis, J. R. (2012). Quantifying the user experience: Practical statistics for user research. Elsevier.

Schütte, R., \& Rotthowe, T. (1998). The Guidelines of Modeling - An Approach to Enhance the Quality in Information Models. Lecture Notes in Computer Science, 1507/1998, 240-254. doi:10.1007/978-3-540-49524$6 \_20$

Shahin, A. (2004). Integration of FMEA and the Kano model: An exploratory examination. International Journal of Quality \& Reliability Management, 21(7), 731-746. doi:10.1108/02656710410549082

Sharp, A., \& McDermott, P. (2008). Workflow modeling: tools for process improvement and applications development. Artech House.

Shen, X. X., Tan, K. C., \& Xie, M. (2000). An integrated approach to innovative product development using Kano's model and QFD. European Journal of Innovation Management, 3(2), 91-99. doi:10.1108/14601060010298435

Shin, N., \& Jemella, D. F. (2002). Business process reengineering and performance improvement - The case of Chase Manhattan Bank. Business Process Management Journal, 8(4), 351-363. doi:10.1108/14637150210435008

Snee, R., \& Hoerl, R. (2003). Leading Six Sigma. Prentice Hall.

Sudha, K., \& Kavita, A. (2019). Implementation of Business Process Re-engineering and its impact on Financial Performance of Banks (With Special Reference to State Bank of India). Advances in Management, 12(1), 71-73.

Tan, K. C., \& Pawitra, T. A. (2001). Integrating SERVQUAL and Kano's model into QFD for service excellence development. Managing Service Quality, 11(6), 418-430. doi:10.1108/EUM0000000006520

Tontini, G. (2007). Integrating the Kano Model and QFD for Designing New Products. Total Quality Management \& Business Excellence, 18(6), 599-612. doi:10.1080/14783360701349351

Tullis, T. S., \& Stetson, J. N. (2004). A comparison of questionnaires for assessing website usability. Paper presented at the Usability professional association conference.

Uluskan, M. (2016). A comprehensive insight into the Six Sigma DMAIC toolbox. International Journal of Lean Six Sigma, 7(4), 406-429. doi:10.1108/IJLSS-10-2015-0040

Valiris, G., \& Glykas, M. (1999). Critical review of existing BPR methodologies. Business Process Management Journal, 5(1), 65-86. doi:10.1108/14637159910249117

Vanderfeesten, I. T. P., Cardoso, J., Mendling, J., Reijers, H. A., \& van der Aalst, W. M. P. (2007). Quality Metrics for Business Process Models. In L. Fischer (Ed.), BPM and Workflow Handbook 2007 (pp. 179-190). Future Strategies.

Vergidis, K., Tiwari, A., \& Majeed, B. (2006). Business Process Improvement using multi-objective optimisation. BT Technology Journal, 24(2), 229-235. doi:10.1007/s10550-006-0065-2

Vignesh, V., Suresh, M., \& Aramvalarthan, S. (2016). Lean in service industries: A literature review. Paper presented at the IOP Conference Series: Materials Science and Engineering.

Wirtz, J., \& Lovelock, C. (2016). Services marketing: People, technology, strategy. World Scientific Publishing Co Inc. doi:10.1142/y0001

Wohlin, C., Runeson, P., Höst, M., Ohlsson, M. C., Regnell, B., \& Wesslén, A. (2012). Experimentation in Software Engineering. Springer. doi:10.1007/978-3-642-29044-2

Womack, J., Jones, D., \& Roos, D. (2000). The machine that changed the world. Free Press.

Yankelevitch, S., \& Kuhl, C. F. (2015). Lean Communication: Applications for Continuous Process Improvement. Business Expert Press. 
Zairi, M., \& Sinclair, D. (1995). Business process re-engineering and process management - a survey of current practice and future trends in integrated management. Business Process Re-engineering \& Management Journal, 1(1), 8-30. doi:10.1108/14637159510798248

Zellner, G. (2011). A Structured Evaluation of Business Process Improvement Approaches. Business Process Management Journal, 17(2), 203-237. doi:10.1108/14637151111122329

Zellner, G. (2013). Towards a framework for identifying business process redesign patterns. Business Process Management Journal, 19(4), 600-623. doi:10.1108/BPMJ-Mar-2012-0020 


\section{ENDNOTES}

1 The map can also be downloaded at: https://tinyurl.com/y4m9weyu

2 Original items according to Brooke (1986): (1): I think that I would like to use this system frequently, (2): I found the system unnecessarily complex, (3): I thought the system was easy to use, (4): I think that I would need the support of a technical person to be able to use this system, (5): I found that the various functions in this system were well integrated, (6): I thought that there was too much inconsistency in this system, (7): I would imagine that most people would learn to use this system very quickly, (8) I found the system very cumbersome to use, (9): I felt very confident using the system, (10): I needed to learn a lot of things before I could get going with this system.

$3 \quad$ Items according to Maes \& Poels (2007): "PEOU 1: It was easy for me to understand what the conceptual model was trying to model", "PEOU 2: Using the conceptual model was often frustrating", "PEOU 3: Overall, the conceptual model was easy to use", "PEOU 4: Learning how to read the conceptual model was easy".

$4 \quad$ PEOU 1: "It was easy for me to understand what knowledge the map was trying to model"; PEOU 2: "Using the map was often frustrating"; PEOU 3: "Overall, the map was easy for me to use"; PEOU 4: "Learning how to read the map was easy for me".

$5 \quad$ Item 1: "It think that I would use the map frequently"; item 2: "I found the map unnecessarily complex"; item 3: "I thought the map was easy to use"; item 4: "I was overstrained with the map and would need the support of an advisor to be able to use the map"; item 5: "The benefits of the map became obvious to me"; item 6: "Some aspects of the map do not make sense"; item 7: "I would imagine that most people would learn how to use this map very quickly"; item 8: "I found the map very cumbersome to use"; item 9: "I felt very confident using the map"; item 10: "I still have to learn a lot more about BPI before I can purposefully use the map".

6 For instance, the FMEA is criticised for being prone to user subjectivity when rating the severity of process weaknesses (cf. Shahin, 2004).

Florian Johannsen is a professor for Enterprise Application Systems at the University of Applied Sciences in Schmalkalden (Germany). In prior, he was a visiting professor at the University of Bremen. He did his doctoral thesis as well as habilitation at the University of Regensburg, where he worked as a research assistant. His areas of interest are Business Process Improvement, Quality Management, Process Modeling and Digital Transformation.

Philipp Griesberger is working as a software engineer at the cooperative DATEV eG. Prior to this he published articles on writing about patterns for business process improvement. 